05,07

\title{
Доменная структура и микромеханизмы перемагничивания в квазидвумерных обменно-смещенных наномагнетиках
}

\author{
(C) В.С. Горнаков ${ }^{1}$, И.В. Шашков ${ }^{1}$, М.А. Лебедкин ${ }^{2}$, Т.А. Лебедкина ${ }^{2}$ \\ ${ }^{1}$ Институт фоизики твердого тела РАН, \\ Черноголовка, Россия \\ ${ }^{2}$ Laboratoire d'Etude des Microstructures et de Mécanique des Matériaux, \\ Université de Lorraine, CNRS, Arts et Métiers ParisTech, \\ Metz, France \\ E-mail: gornakov@issp.ac.ru
}

\begin{abstract}
С использованием комплексного метода магнитооптических индикаторных пленок и акустической эмиссии изучены доменная структура и микромеханизмы перемагничивания в квазидвумерных обменно-смещенных поликристаллических наномагнетиках $\mathrm{NiFe} / \mathrm{FeMn}$ и $\mathrm{NiFe} / \mathrm{NiO}$. Показано, что наличие дисперсии осей однонаправленной анизотропии в зернах антиферромагнитного слоя определяет статистическое распределение и хиральность спиновых пружин вблизи интерфейса. Обнаружены сигналы акустической эмиссии, обусловленные возбуждением упругих волн Лэмба при перемагничивании $\mathrm{NiFe} / \mathrm{NiO}$ гетероструктур. Показано, что коэрцетивность таких гетероструктур связана с необратимыми процессами преодоления потенциальных барьеров, вызваных формированием разнохиральных спиновых пружин, локализованных в антиферромагнетике, непосредственно вблизи границы „ферромагнетик-антиферромагнетик“.
\end{abstract}

Организация финансирующая выполнение работы: Институт физики твердого тела РАН (Программа РАН „Наноструктуры“).

DOI: $10.21883 /$ FTT.2018.11.46661.19NN

\section{1. Введение}

Тонкопленочные ферромагнетики (ФМ), связанные с антиферромагнетиком (АФМ) обменным взаимодействием на границе их раздела, отличаются от объемных ферромагнетиков нарушенной магнитной симметрией, заключающейся в энергетической неэквивалентности переключения намагниченности в противоположных направлениях. Такая ФМ/АФМ-гетероструктура характеризуется однонаправленной (обменной) анизотропией, которая проявляется через сдвиг и уширение петли гистерезиса ФМ-слоя [1]. При этом ключевую роль в формировании обменной анизотропии играет распределение и эволюция спинов, локализованных в антиферромагнетике непосредственно вблизи межфазной границы [2-5]. В настоящее время известно несколько моделей, объясняющих как сдвиг петли гистерезиca $[2,3,6-8]$, так и увеличение коэрцитивной силы [811] в таких гетероструктурах. Показано, что характер перемагничивания обменно-смещенного ФМ-слоя определяется зарождением и эволюцией обменной спиновой пружины (частичной доменной стенки) в антиферромагнетике вблизи интерфейса. Концепция спиновой пружины предполагает ее закручивание (раскручивание) в АФМ-слое во время перемагничивания ФМ-слоя из основного состояния (в основное) состояние [2,4,5,11-14]. При этом сдвиг петли гистерезиса обусловлен обратимыми процессами переориентации спинов в ФМ-слое и связанных с ними спинов в АФМ-слое [2,3,7]. Напротив, уширение петли гистерезиса связано с необратимыми процессами перераспределения этих спинов $[8,9,11,14]$.
Одна из причин возникновения последних заключается в том, что в реальных двухслойных структурах как внутрислоевые, так и интерфейсные несовершенства могут индуцировать образование обменных пружин с противоположным направлением закручивания, то есть с разной хиральностью, подобно двумерным доменным стенкам в объемных ферромагнетиках $[15,16]$ или спиновым пружинам в обменно-связанных магнитотвердых/магнитомягких ферромагнитных слоях [17-20]. В этом случае, при приложении поля против намагниченности насыщения, разнонаправленное закручивание спинов в соседних областях гетероструктуры приводит к образованию локальных потенциальных барьеров в виде $360^{\circ}$ доменных границ или метастабильных областей с неполной инверсией магнитных моментов. Для преодоления этих барьеров требуется дополнительная энергия, то есть необходимо увеличивать магнитное поле, что и определяет увеличение коэрцитивности. С другой стороны, тепловые флуктуации спинов из метастабильного состояния в энергетически устойчивое определяют наблюдавшийся эффект магнитного последействия [21-23]. Для описания закономерностей формирования коэрцитивной силы и эффектов последействия в реальных магнитных гетероструктурах ФМ/АФМ был предложен ряд моделей, рассматривающих необратимое переключение параметра порядка в поликристаллических зернах в АФМ-слое во время перемагничивания ферромагнетика $[8,9,11]$. Квазидвумерные обменносмещенные наномагнетики ФМ/АФМ с поликристаллическим АФМ-слоем представляют собой структуры, в которых наиболее сильно проявляется влияние диспер- 

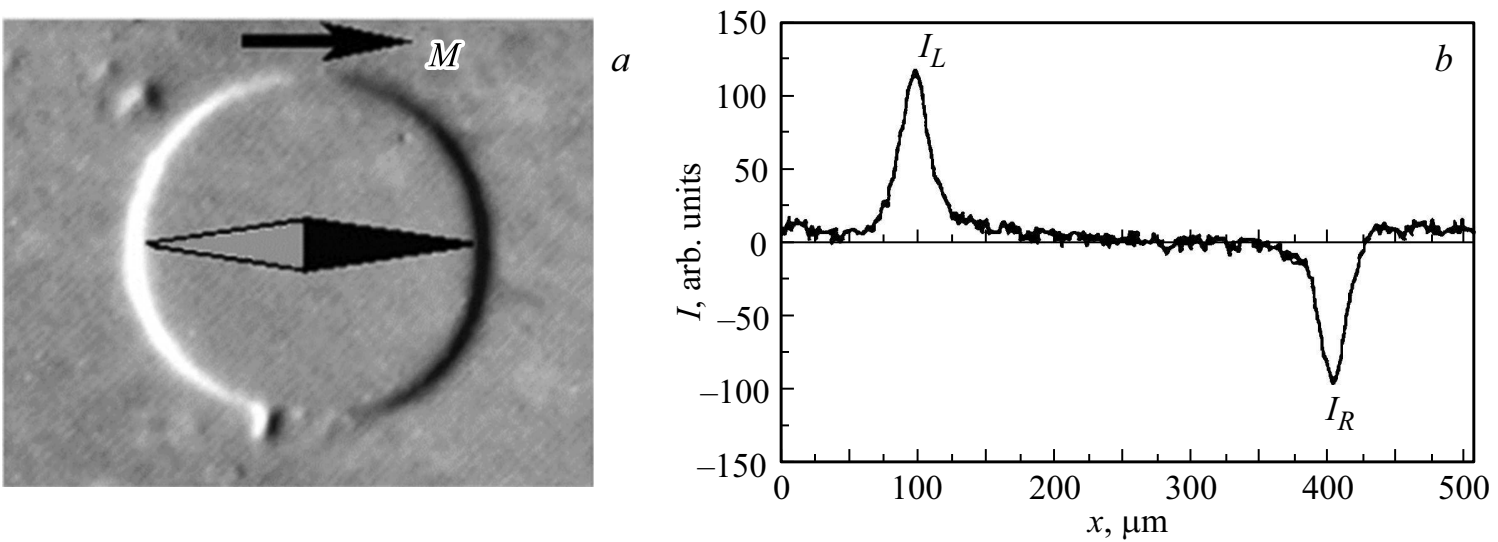

Рис. 1. MO-портрет образца $\mathrm{NiFe} / \mathrm{FeMn}(a)$ и интенсивность MO сигнала вдоль стрелки компаса $(b)$.

сии осей анизотропии в зернах на необратимые процессы перемагничивания в них. Отклонение распределения АФМ-спинов от равновесной конфигурации приводит к метастабильному состоянию, которое проявляется в так называемом тренинг-эффекте. Он заключается в зависимости параметров петли гистерезиса при последовательном циклическом изменении магнитного поля [21-23] и может быть связан с долговременной релаксацией спинов в АФМ-слое. Поскольку преобразование доменной структуры в ФМ/АФМ пленках дает ключ к пониманию механизмов формирования коэрцитивности $[8,9,11]$ и тренинг-эффекта в них, большое значение имеют [21-23] исследования поведения магнитных моментов в ФМ-слое и магнитоупругих свойств в АФМ-слое. В настоящей работе были изучены доменная структура и микромеханизмы перемагничивания в квазидвумерных обменно-смещенных наномагнетиках с использованием магнитооптической визуализации распределения намагниченности в ФМ-слое и регистрации ультразвуковых возбуждений (акустической эмиссии) в АФМ-слое в постоянных и переменных магнитных полях.

\section{2. Эксперимент}

Образцы представляли собой поликристаллические пленки $\mathrm{NiFe}(16 \mathrm{~nm}) / \mathrm{FeMn}(30 \mathrm{~nm})$ и $\mathrm{NiFe}(10 \mathrm{~nm}) / \mathrm{NiO}(50 \mathrm{~nm})$, выращенные магнетронным и ионно-лучевым распылением, соответственно, на окисленных на воздухе кремниевых подложках. Однонаправленная анизотропия наводилась внешним магнитным полем $H=300$ Ое в процессе выращивания образцов. В качестве антиферромагнетика во второй гетероструктуре был выбран оксид никеля $\mathrm{NiO}$, который обладает значительной магнитострикцией благодаря чему при перемагничивании гетероструктуры в ней могут формироваться и регистрироваться магнитоупругие возбуждения. В качестве ферромагнетика был выбран пермаллой $\mathrm{Ni}_{79} \mathrm{Fe}_{21}$, в котором, наоборот, величина магнитострикции, практически, равна нулю. Следовательно, ФМ-пленка не дает магнитоупругого вклада в регистрируемый сигнал образцов, то есть появление такого сигнала будет связано исключительно с преобразованием системы спинов локализованных в АФМ-слое.

Микроскопическое исследование процессов перемагничивания в ФМ/АФМ-гетероструктуре осуществлялось путем визуализации магнитных полей рассеяния в отраженном линейно поляризованном свете с использованием метода магнитооптической индикаторной пленки (МОИП) [19,24]. Основу индикатора составляет тонкая пленка железоиттриевого граната допированного висмутом с плоскостной намагниченностью, обладающая большим эффектом Фарадея. При помещении индикатора на поверхность ФМ/АФМ-образца нормальные компоненты локальных полей рассеяния $H_{\perp}$ ФМ-слоя вызывают соответствующее локальное отклонение намагниченности индикатора от его плоскости. Благодаря двойному эффекту Фарадея нормальная компонента магнитного момента индикатора инициирует вращение плоскости поляризации света, отраженного от прилегающей к образцу поверхности, и, в зависимости от величины и знака локального поля $H_{\perp}$, визуализируется как темные или светлые области на сером фоне магнитооптического (MO) портрета образца. Для выявления закономерностей формирования обменных пружин использовали регистрацию МО-изображения во вращающемся магнитном поле. Для анализа намагниченности в плоскости образцов в нем проделывалось сквозное круглое отверстие диаметром $300 \mu \mathrm{m}$ (рис. 1,a). Направление эффективной намагниченности $\mathbf{M}$, формирующейся во внешних магнитных полях, определялось по ориентации оси симметрии (показана стрелкой) магнитооптического портрета, формируемого компонентами поля рассеяния на краю круглого отверстия. Количественной характеристикой $M$ служит усредненная величина интенсивности магнитооптического сигнала $I_{A}=\left(I_{L}+I_{R}\right) / 2$, где $I_{L}$ и $I_{R}$ - максимальные значения интенсивности на „темном“ и „светлом“ краях. Эта величина определяется углом фарадеевского вращения плоскости поляризации света, пропорционального перпендикулярной полю $H_{\perp}$ на краю отверстия и, следовательно, усредненной по 

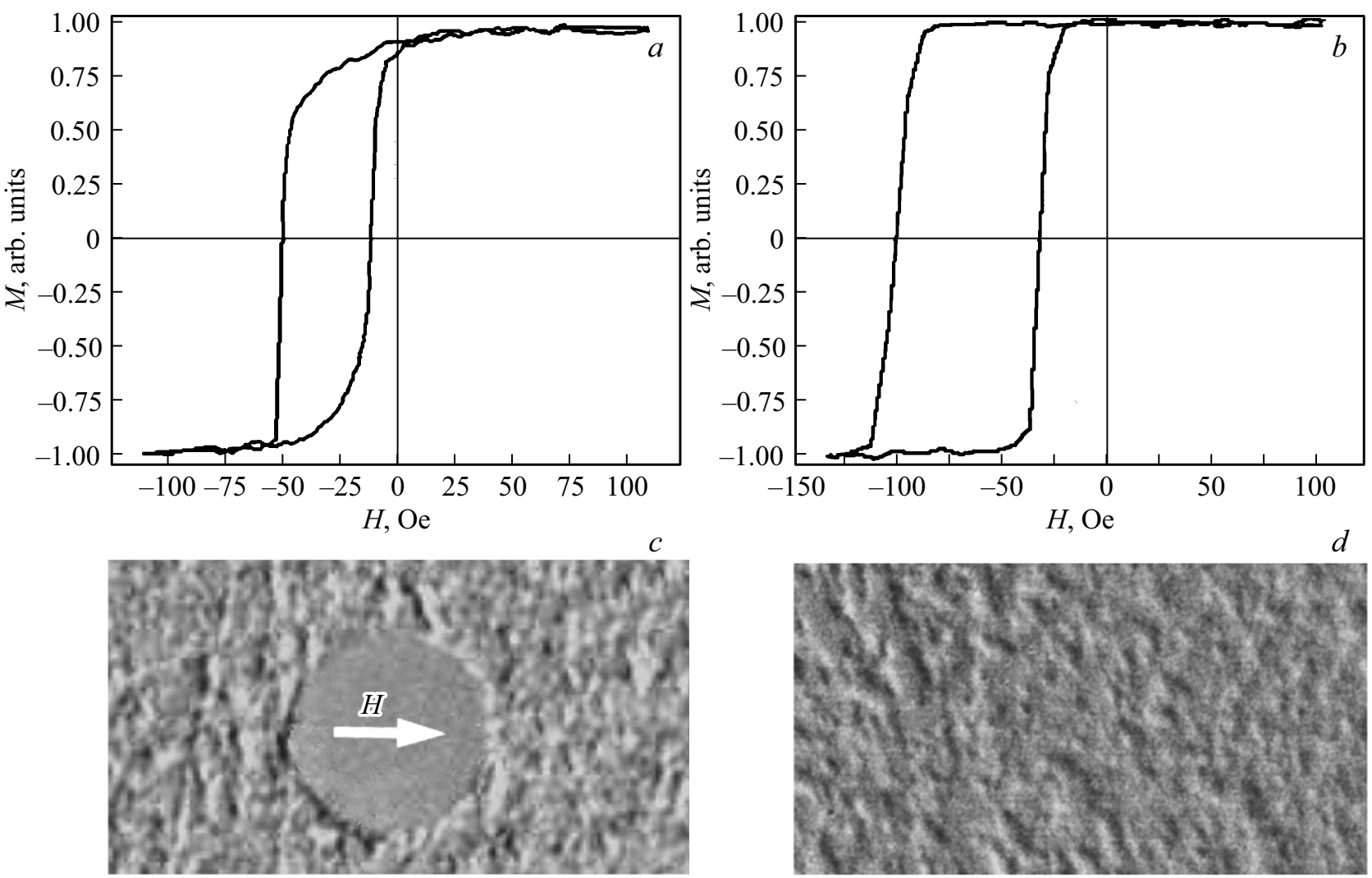

Рис. 2. Петли гистерезиса $(a),(b)$ и МОИП изображения доменной структуры $(c)$, $(d)$ гетероструктур $\mathrm{NiFe} / \mathrm{FeMn}(a)$, $(c)$ и $\mathrm{NiFe} / \mathrm{NiO}(b),(d)$ при перемагничивании вдоль оси однонаправленной анизотропии. Магнитное поле при МО-регистрации равнялось $51.0 \mathrm{Oe}(c)$ и $103.0 \mathrm{Oe}(d)$.

толщине образца намагниченности. Измерения петель гистерезиса были получены с помощью вибромагнитометра при ориентации поля вдоль осей ФМ/АФМ-гетероструктур при комнатной температуре.

Для регистрации упругих возбуждений, обусловленных деформацией образца, возникающих в поликристаллических гетероструктурах с магнитострикционным антиферромагнитным слоем $\mathrm{NiO}$, использовался метод акустической эмиссии. Используемый для исследований пластичности [25-27], этот метод был адаптирован для выявления магнитоупругих эффектов в пленках [28]. Образец и пьезоэлектрический датчик, располагающийся на поверхности образца через прослойку смазки для лучшего контакта с этой поверхностью, помещались в однородное магнитное поле. Рабочая полоса частот датчика была с в диапазоне $200-900 \mathrm{kHz}$. Захваченный сигнал АЭ предварительно усиливался на $60 \mathrm{~dB}$ и записывался в память компьютера с частотой дискретизации $2 \mathrm{MHz}$. Для проверки акустического контакта между образцом и датчиком и получения характеристик импульсного отклика собственно датчика был выполнен стандартный тест (Hsu-Nielsen source) [29], заключающийся в резком однократном механическом воздействии на столик вблизи образца с датчиком. Импульсная характеристика имеет время нарастания около нескольких микросекунд и затухает в течение нескольких миллисекунд. Спектр его частот лежит в полосе ниже $50 \mathrm{kHz}$.

\section{3. Результаты и обсуждение}

На рис. 2 приведены петли гистерезиса гетероструктур и характерная доменная структура при их перемагничивании вдоль оси однонаправленной анизотропии. Поля смещения петли гистерезиса и коэрцитивности для гетероструктуры $\mathrm{NiFe} / \mathrm{FeMn}$ были 33 и 19 Ое соответственно и для гетероструктуры $\mathrm{NiFe} / \mathrm{NiO}-67$ и $31 \mathrm{Oe}$ соответственно.

Переключение намагниченности как в $\mathrm{NiFe} / \mathrm{FeMn}$ (рис. 2,c), так и в $\mathrm{NiFe} / \mathrm{NiO}$ (рис. 2,d) происходит за счет неоднородного перемагничивания с образованием нерегулярной доменной структуры. Таким образом, визуализация доменной структуры показала, что в процессе перемагничивания таких гетероструктур решающую роль играют микроскопически неоднородные спиновые состояния.

Для изучения роли обменной пружины в формировании гистерезисных свойств в поликристаллических ФМ/АФМ двухслойных пленках мы использовали визуализацию доменной структуры в $\mathrm{NiFe} / \mathrm{FeMn}$ во вращающемся в плоскости образца магнитном поле $H$ (рис. 3) 


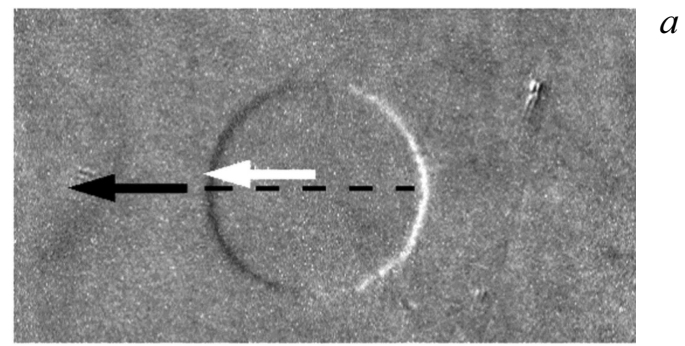

$a$
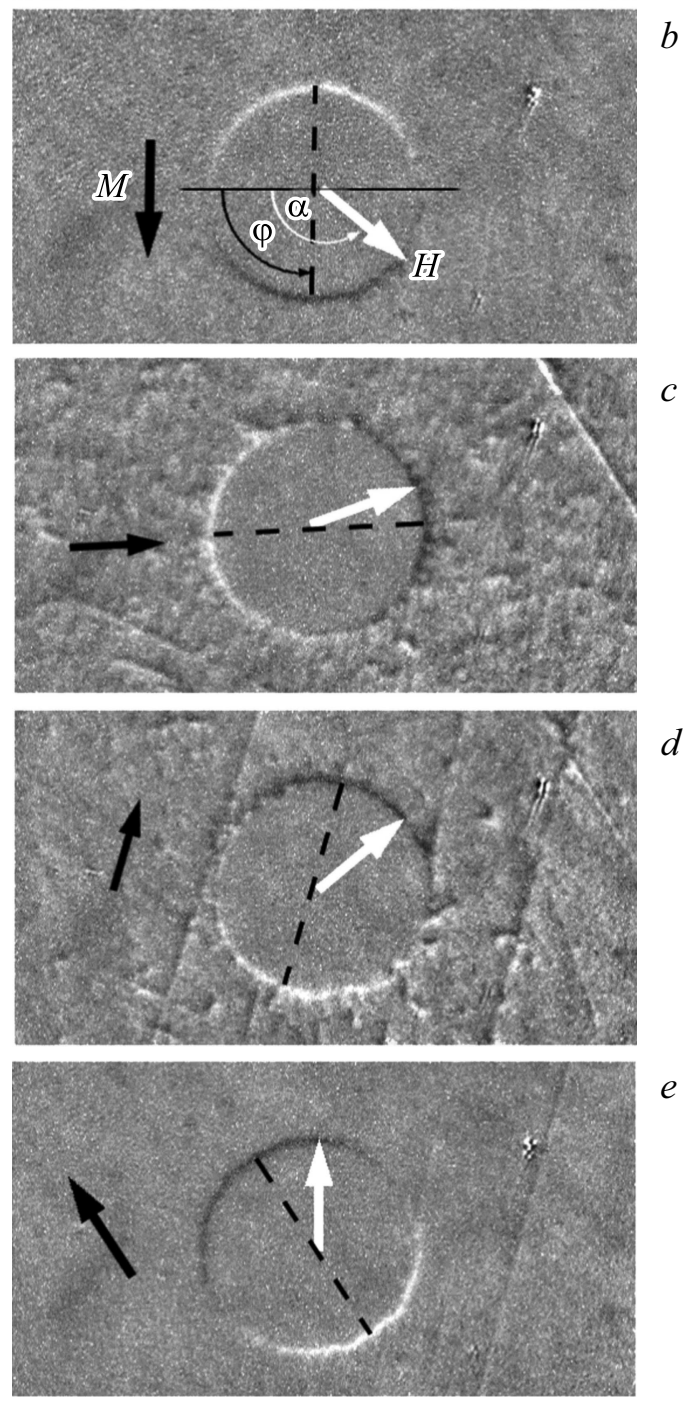

Рис. 3. МОИП- изображения доменной структуры во вращающемся поле $H=30 \mathrm{Oe}$. Моменты регистрации отмечены на рис. 4 теми же буквами. Белая стрелка показывает направление $\mathbf{H}$, черная стрелка и пунктирная линия показывают направление М, полученное из анализа МО-контраста по краю отверстия.

вблизи отверстия в образце. Результаты зависимости угла поворота $\varphi$ усредненной по толщине $Ф$ М-слоя намагниченности $M$ относительно оси однонаправленной анизотропии от угла поворота $\alpha$ магнитного поля $H$ при различных его значениях приведены на рис. 4. Штриховой линией показано состояние, при котором ориентация намагниченности совпадала бы с направлением поля. Показано, что в достаточно большом поле ( $\sim 60$ Ое) $M$ вращается практически синхронно с полем, лишь незначительно отставая от $H$ при $\alpha<180^{\circ}$ и опережая $H$ при $\alpha>180^{\circ}$. При этом наблюдается незначительный гистерезис при вращении поля по и против часовой стрелки. Однако, с уменьшением величины поля гистерезис и рассогласование между ориентацией $N$ и $H$ становятся более выраженными. Такое поведение намагниченности связано с преобразованием доменной

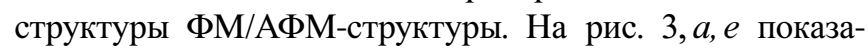
ны МОИП-изображения распределения намагниченности при вращении поля $H=30.0$ Ое против часовой стрелки при ориентациях поля, указанных на рис. 4 теми же буквами. На начальном этапе вращение $M$ из исходного состояния (рис. $3, a$ ) происходит практически однородно (рис. $3, b$ ), что можно видеть по отсутствию магнитных неоднородностей в плоскости образца и вращению черно-белого контраста на краю отверстия. При приближении угла $\alpha$ к $180^{\circ}$ в образце возникает неоднородный МО-контраст (рис. $3, c, d$ ), указывающий на неоднородное перераспределение намагниченности в ФМ-слое. Процесс преобразования доменной структуры характеризуется изменением положения намагниченности $M$ относительно $H$. Если вначале $M$ отставала от поля (рис. $3, c$ ), то с увеличением угла $\alpha M$ стала опережать поле (рис. $3, d$ ). Дальнейшее увеличение угла $\alpha$ приводит к однородному и когерентному с $H$ вращению намагниченности (рис. $3, e$ ) и ее окончательной ориентации вдоль поля (рис. $3, a$ ). Процесс перемагничивания образца при вращении поля в противоположном направлении (по часовой стрелке) происходит аналогично, но с определенным гистерезисом.

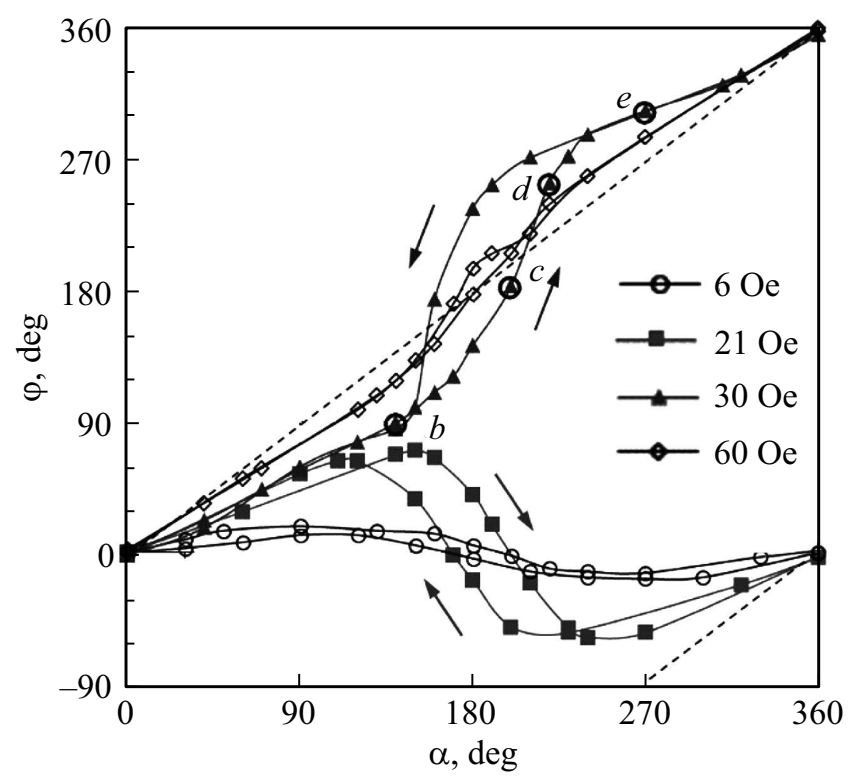

Рис. 4. Зависимость угла поворота $\varphi$ намагниченности М от направления (угла $\alpha$ ) поля $\mathbf{H .}$ 

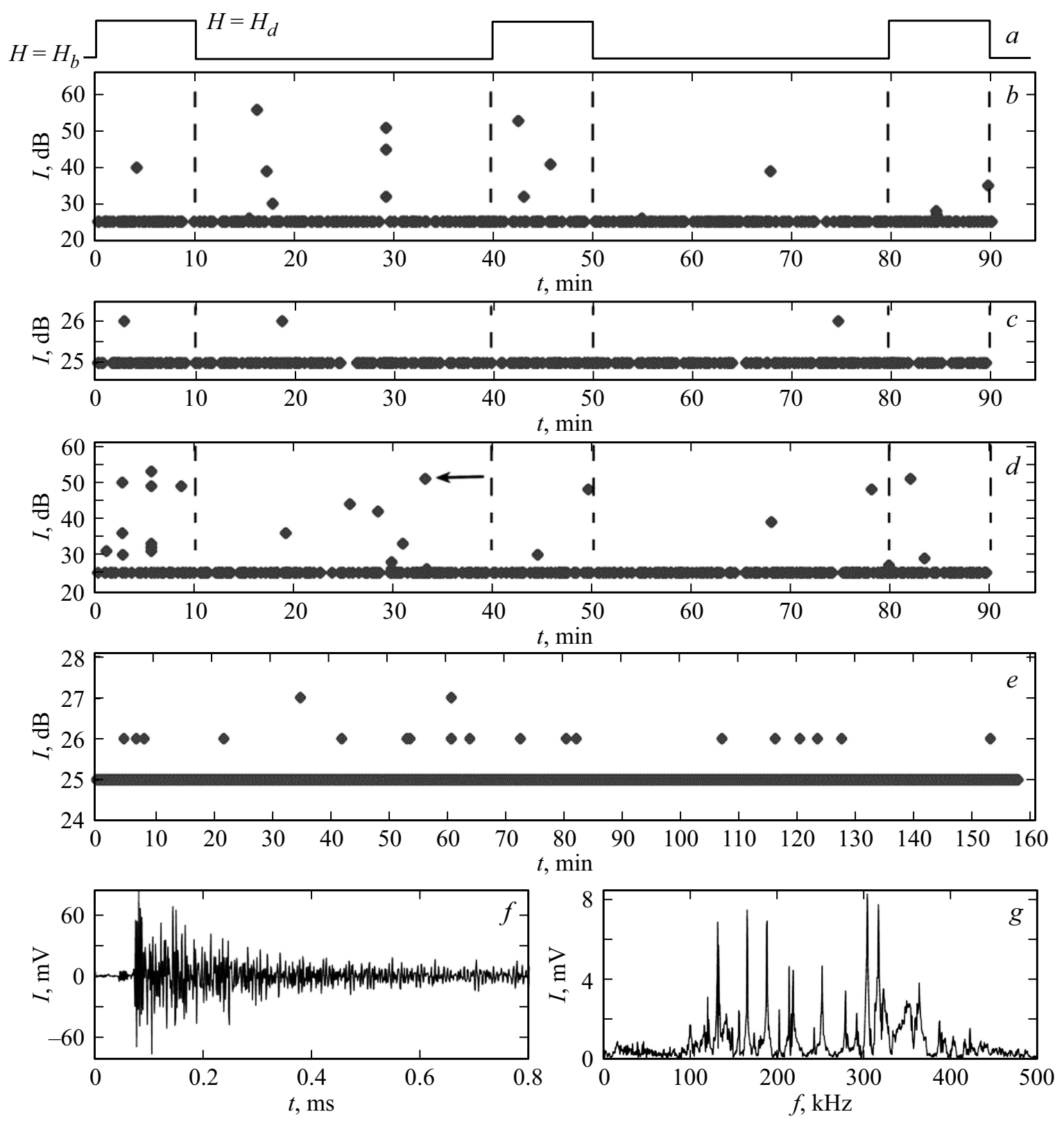

Рис. 5. Акустический отклик образца $\mathrm{NiFe} / \mathrm{NiO}(1 \times 1)$ см в импульсном магнитном поле $(a)$, ориентированном антипараллельно $(b)$, параллельно $(c)$ и перпендикулярно $(d)$ полю однонаправленной анизотропии и отклик в отсутствие образца $(e)$. Упругие колебания $(f)$ и их спектр $(g)$ соответствующие акустическому сигналу, обозначенному стрелкой на панели $(d)$.

При дальнейшем уменьшении величины поля ниже критической величины $H_{\mathrm{CR}} \approx 28$ Ое характер зависимости $\varphi(\alpha)$ меняется коренным образом. На рис. 4 видно, что при $H=21.0 \mathrm{Oe}$ намагниченность на начальном этапе также следует за полем с некоторым отставанием. Однако, в отличие от случая больших полей, при дальнейшем увеличении угла $\alpha$ угол $\varphi$, убывает, а МО-контраст в некоторой области углов вблизи $\alpha=180^{\circ}$ также становится неоднородным, указывая на неоднородное распределение намагниченности. Как и в случае больших полей, такое преобразование намагниченности обусловливает гистерезис при вращении поля в противоположных направлениях. В слабых полях (например, при $H=6.0$ Ое на рис. 4) магнитный момент слабо отклоняется от исходного состояния и не вызывает сколь-нибудь заметного изменения МО-контраста в плоскости образца.

Очевидно, что решающую роль в формировании гистерезисных свойств обменно-смещенных поликристаллических наномагнетиков играют не только наблюдаемые в эксперименте локальные преобразования магнитных моментов в ФМ-слое, но и спиновых состояний в АФМ-слое. Экспериментально изучить фактическое преобразование системы спинов, локализованных в АФМ-зернах, общедоступными методами магнетометрии не представляется возможным ввиду отсут- 

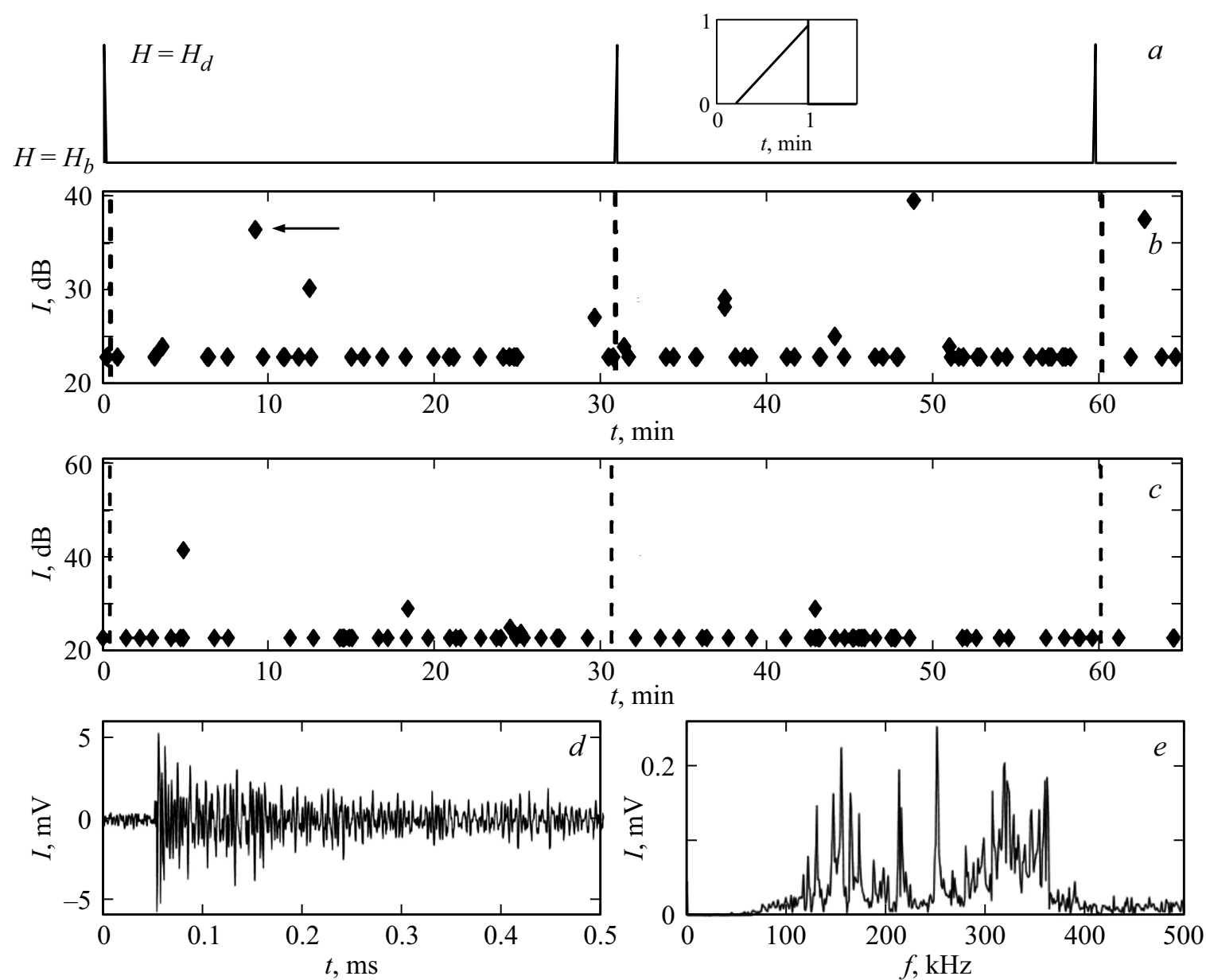

Рис. 6. Акустический отклик образца $\mathrm{NiFe} / \mathrm{NiO}(1 \times 0.5)$ см в пилообразном магнитном поле $(a)$, ориентированном перпендикулярно $(b)$ и параллельно $(c)$ полю однонаправленной анизотропии. Упругие колебания $(d)$ и их спектр $(e)$ соответствующие акустическому сигналу, обозначенному стрелкой на панели $(d)$.

ствия эффективной намагниченности в них. Возможность регистрации изменения спиновых состояний в АФМ-слое в результате перемагничивания гетероструктуры ФМ/АФМ появляется, если в качестве АФМ-слоя использовать магнитострикционный материал. Идеальным кандидатом для этого является оксид никеля. Моменты быстрого изменения направления магнитных моментов в зернах $\mathrm{NiO}$ будут приводить к их резким деформациям и, как следствие, к возбуждению ударных упругих волн, акустическая эмиссия которых может регистрироваться пьезодатчиком. А чтобы не смешивать акустические возбуждения в АФМ-слое с такими возможными возбуждениями в ФМ-слое, в качестве этого слоя необходимо выбрать материал с нулевой магнитострикцией. Таким материалом является пермаллой $\mathrm{Ni}_{79} \mathrm{Fe}_{21}$.

K образцам $\mathrm{Ni}_{79} \mathrm{Fe}_{21} / \mathrm{NiO}$ площадью $(1 \times 1) \mathrm{cm}$ и $(1 \times 0.5)$ см прикладывались прямоугольное с (рис. $5, a)$ и пилообразное (рис. 6, $a$ ) импульсные поля, соответственно. Амплитуда импульсов $H_{d}=200$ Ое выбиралась таким образом, чтобы ФМ-слой также, как и в основном состоянии (при $\left.H_{b}=0 \mathrm{Oe}\right)$, намагничивался до насыще- ния, что контролировалось МО-измерениями. При этом никаких сигналов АЕ не наблюдалось при переключении магнитного поля с временами нарастания импульса, изменяющимися в широком диапазоне от $1 \mathrm{~ms}$ (рис. $5, a)$ до $1 \mathrm{~s}$ (рис. 6,a). Напротив, одиночные акустические возбуждения были обнаружены в состоянии насыщения гетероструктур как в поле $H_{b}$, так и в поле $H_{d}$ при регистрации сигнала АЭ в течение достаточно длительного времени ожидания после переключения поля. Сигналы АЭ наблюдались как при премагничивании образцов параллельно (рис. 5, $b$ и 6,c), так и перпендикулярно (рис. 5, $d$ и $6, b$ ) оси однонаправленной анизотропии. Ряд точек на рис. 5 представляют собой сигналы АЕ, записанные в полях, направленных антипараллельно (рис. 5,b) и параллельно (рис. 5,c) полю обменного смещения. В первом случае величины акустических сигналов значительно превышали собственный шум регистрирующей аппаратуры, который измерялся в отсутствие образца в течение длительного времени (рис. $5, e$ ). Во втором случае (рис. 5,c) вероятность появления сигналов АЭ была крайне мала. 
После включения или выключения поля амплитуды акустических возбуждений и моменты их появления были распределены случайным образом. При продолжительном циклировании магнитного поля вероятность появления событий АЕ снижалась (рис. 5, $b$ ), что свидетельствует о стремлении системы спинов в АФМ-слое прийти в более стабильное состояние. А после прекращения действия импульсов поля вероятность возбуждения $\mathrm{AE}$ со временем уменьшалась, практически, до нуля. Стоит отметить, что вероятность появления акустических возбуждений зависит от магнитной предыстории образцов. В частности, переключение магнитного поля с параллельной ориентации (рис. $5, b, 6, c)$ на перпендикулярную (рис. 5, $d, 6, c)$ (или наоборот) приводит к увеличению вероятности появления акустических возбуждений.

Поскольку большинство измереных величин аккустического сигнала существенно превышало уровень собственного шума пьезодатчика, то можно сделать вывод, что описанные выше события AE вызваны упругими волнами, возбуждаемыми в гетероструктуре $\mathrm{NiFe} / \mathrm{NiO}$. На рис. $5, f$ и $6, d$ показаны две типичные формы затухающих колебаний сигналов АЭ, записанные в моменты событий (указанные стрелками на рис. 5,d и 6,b) после снятия перпендикулярного поля для двух образцов, различающихся размерами и формой. На рис. $5, g$ и $6, e$ представлены соответствующие им спектры Фурье. В обоих случаях, вне зависимости от формы и размера образцов, спектры упругих колебаний имеют, практически, идентичный набор гармоник, лежащий в диапазоне от $100 \mathrm{kHz}$ до $400 \mathrm{kHz}$, а времена затухания в пределах десятых долей милисекунд, что значительно отличается от области собственных частот колебаний $(0-50 \mathrm{kHz})$ и времен затухания (нескольких милисекунд) отклика датчика на стандартный тест (Hsu-Nielsen source). Следует отметить, что полученные спектры хотя и близки по составу гармоник, но существенно различаются по амплитуде. Анализ большого числа измерений сигналов АЭ позволяет заключить, что события АЕ с разными амплитудами, записанные в разных полях, в образцах с разными размерами, в разные моменты времени и, в разных местах имеют одинаковые частотные спектры. Таким образом, можно констатировать, что спектры Фурье, приведенные на рис. 5,g и 6,e отражают свойства ультразвуковой волны, возбуждаемой в исследуемой среде в результате ее ударной деформации.

Акустический датчик реагирует на упругие поверхностные волны с вертикальной поляризацией, то есть нормальной к поверхности. В тонких пластинках и пленках с такой поляризацией могут возбуждаться так называемые волны Лэмба [30-32]. Параметры этих волн определяются толщиной пленки и структурой материала, в частности, анизотропией упругих взаимодействий [33]. Поэтому наличие мод упругих колебаний, присутсвующих в спектрах Фурье, указывает на возбуждение в гетероструктуре волн Лэмба. Принимая

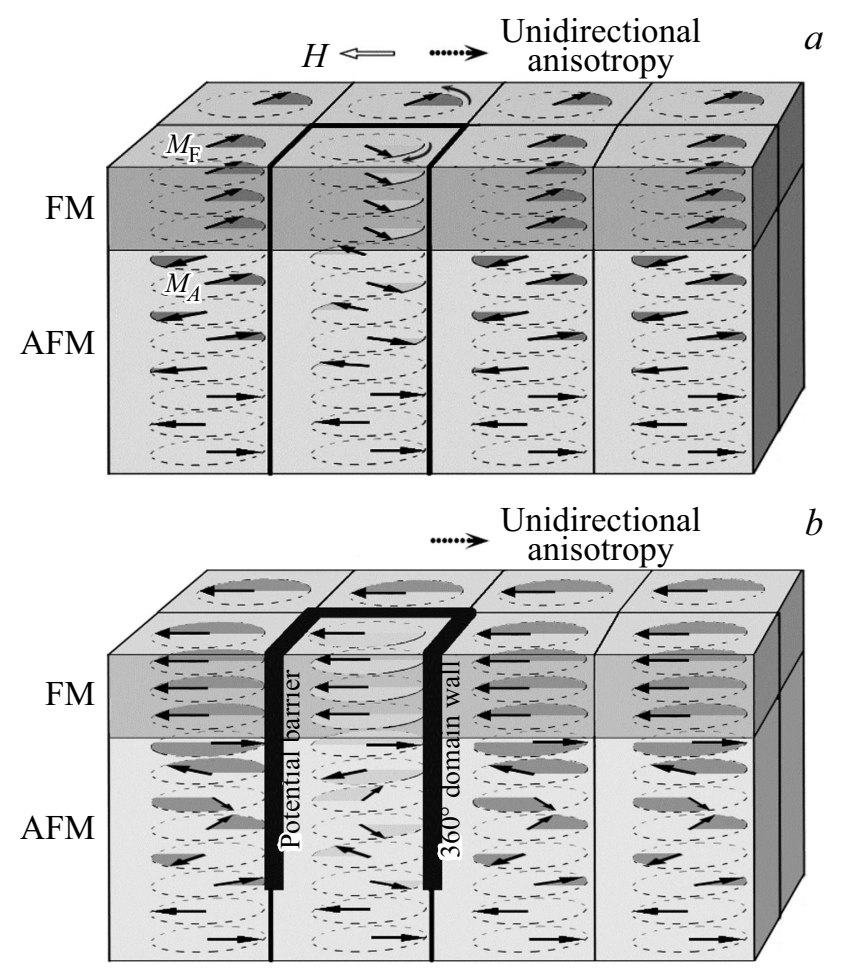

Рис. 7. Схематическое изображение распределения магнитных моментов в ФМ- и АФМ-слоях обменно-смещенной гетероструктуры, содержащей зерно с инверсной спиновой спиралью, до ее перемагничивания $(a)$ и после $(b)$.

во внимание, практически, нулевую магнитострикцию в $\mathrm{NiFe}$, можно заключить, что возбуждение упругих колебаний происходит в антиферромагнитном слое $\mathrm{NiO}$ за счет переключения системы спинов, инициированного вращением спинов в ферромагнитном слое $\mathrm{NiFe}$ благодаря обменному взаимодействию ФМ- и АФМ-спинов на интерфейсе.

Зарождение доменов и движение доменных стенок в двухфазной пленке (рис. 2) приводят к неоднородному вращению спинов в обоих ФМ- и АФМ-слоях вблизи границы раздела $[2,14,15]$. Из-за дисперсии осей анизотропии в АФМ-зернах когерентное вращение ФМ-спинов в магнитном поле сопровождается образованием в этих зернах локальных спиралей с право- и (или) левовинтовым закручиванием спинов (рис. 7, $a$ ). В результате образуются метастабильные состояния, характеризующиеся формированием $360^{\circ}$ топологических доменных границ (рис. 7,b). Возникшие потенциальные барьеры для релаксации гетероструктуры в более стабильное состояние не могут быть преодолены без приложения дополнительной энергии. Наличие барьеров обусловливает необратимые процессы резкого перехода между двумя вырожденными состояниями намагниченности АФМ-зерен $[9,11]$ и возбуждение упругих волн из-за магнитострикции. Важно отметить, что такие переходы должны быть также термоактивоционными и зависеть от предыстории и количества повторений импульсов поля. 
В рамках данной модели могут быть реализованы два конкретных микромеханизма [9]. Первый, это когда эффективный средний угол некоторых обменных спиновых пружин в антиферромагнетике превышает критическое значение [11] и АФМ-зерна переходят в другое состояние за счет преодоления барьеров. Подавляющее большинство таких процессов реализуется при движении гибридных ФМ/АФМ доменных границ [5] и потому статистически усредняясь эти процессы не дают вклада в магнитострикционный отклик при измерениях АЭ во время перемагничивания $\mathrm{NiFe} / \mathrm{NiO}$ гетероструктур. При этом затраты приложенной энергии и соответствующий гистерезисный эффект являются результатом необратимого переключения состояния спинов в АФМ- зернах. Однако, некоторые достаточно высокие энергетические барьеры не могут быть преодолены в течение или сразу после переключения намагниченности. Таким образом, образец будет находиться в метастабильном состоянии с энергией, определяемой зернами с закрученными спинами. Возвращение в стабильное состояние потребует термически активированных раскручивающих процессов, которые могут быть реализованы за счет зарождения и движения доменных $T$-стенок, что приведет к вращению спинов в $\mathrm{NiO}$ зернах и, соответственно, к переориентации оси анизотропии и магнитострикционной деформации зерен. Резкое изменение размера изолированных зерен, вызванное их деформацией, приведет к возникновению ударной волны, которая и может возбуждать наблюдаемые волны Лэмба.

Второй возможный механизм возбуждения упругих волн представляет собой процесс парной рекомбинации $T$-стенок в скрученных NiO зернах [32]. T-стенки могут легко зарождаться, перемещаться и аннигилировать при возникновении внутренних напряжений в процессе деформации некоторых зерен из-за вращения в них спинов. Накопленная в двух стенках упругая энергия может быть высвобождена в процессе их аннигиляции в виде импульса упругой сдвиговой волны, которая будет распространяться вдоль слоя $\mathrm{NiO}$ в виде волн Лэмба. Таким образом, наблюдаемые при перемагничивании $\mathrm{NiFe} / \mathrm{NiO}$ гетероструктур магнитоупругие возбуждения убедительно показывают, что коэрцитивность таких гетероструктур связана с необратимыми процессами преодоления потенциальных барьеров, вызванных формированием разнохиральных спиновых пружин, локализованных в антиферромагнетике, непосредственно вблизи границы ФМ-АФМ.

Наличие дисперсии осей однонаправленной анизотропии в зернах определяет статистическое распределение и хиральность спиновых пружин вблизи интерфейса под действием магнитных полей. При перемагничивании таких гетероструктур вдоль оси однонаправленной анизотропии противоположные направления закручивания спинов является равновероятными и потому эффективная намагниченность не меняет своей ориентации (рис. $2, b$ ). Во вращающихся магнитных полях хиральная симметрия нарушается. В больших полях анизотропия во всех зернах преодолевается и происходит квазинепрерывное вращение намагниченности (рис. 4, кривая при $H=60 \mathrm{Oе}$ ), то есть формируются монохиральные обменные пружины. В слабых полях, наоборот, спины в зернах испытывают слабое возмущение не способное преодолеть анизотропию в большинстве зерен (рис. 4, кривая при $H=6 \mathrm{Oe})$. В промежуточных полях в процессе вращения поля в одной части зерен анизотропия преодолевается и направление закручивания спиновых пружин в них совпадает с направлением вращения поля, а в другой части не преодолевается - и спиновые пружины в них закручиваются в противоположном направлении, возвращаясь в исходное состояние при завершении цикла поворота поля или оставаясь в метастабильном состоянии. Соотношение объема зерен, которые могут следовать за полем, к объему зерен, которые не могут следовать за полем, должно зависеть от величины поля. Изменение характера зависимости $\varphi(\alpha)$ при отклонении величины поля от $H=H_{\mathrm{CR}}$ в ту или другую сторону подтверждает эту зависимость (рис. 4, кривые при $H=30 \mathrm{Oe}$ и $21 \mathrm{Oe}$ ).

\section{4. Заключение}

Визуализация доменной структуры в гетероструктуре $\mathrm{NiFe} / \mathrm{FeMn}$ и измерения сигнала АЭ в гетероструктуpe $\mathrm{NiFe} / \mathrm{NiO}$ показали, что в процессе переключения намагниченности в таких гетероструктурах решающую роль играют микроскопически неоднородные спиновые состояния. При регистрации акустической эмиссии в гетероструктуре $\mathrm{NiFe} / \mathrm{NiO}$ обнаружены стохастические акустические сигналы, вызванные упругими волнами Лэмба. Эти волны возбуждаются деформацией при резком переключении хиральности магнитных моментов в отдельных зернах антиферромагнетика $\mathrm{NiO}$, обладающего сильной магнитострикцией. Соответствующие моды деформации связаны с необратимыми изменениями первоначальной ориентации спинов, которые могут иметь место в некоторых антиферромагнитных зернах с неупорядоченными осями анизотропии при перемагничивании обменно-связанных структур ферромагнетик/антиферромагнетик. Установлено, что под действием поля, антипараллельного оси однонаправленной анизотропии, в различных участках пленки антиферромагнетика формируются спиновые пружины с противоположной хиральностью. Их баланс приводит к уменьшению эффективной намагниченности ферромагнитного слоя без его вращения. Показано, что отклонение поля от оси анизотропии приводит к нарушению баланса и, как следствие, к вращению намагниченности. Во вращающемся плоскостном магнитном поле $H<H_{\mathrm{CR}}$ наблюдается инверсное вращение намагниченности, тогда как при $H>H_{\mathrm{CR}}$ вращение намагниченности, практически, однонаправленное, отвечающее монохиральной спиновой пружине в АФМ-слое. 
Показано, что определяющим фактором увеличения коэрцетивности в данной двухфазной системе является дисперсия осей кристаллографической анизотропии в зернах антиферромагнитного слоя вблизи межфазной поверхности, что приводит к возникновению метастабильных состояний с топологическими барьерами, разделяющими области кристалла с разнохиральными обменными пружинами.

\section{Список литературы}

[1] W.H. Meiklejohn, C.P. Bean. Phys. Rev. 102, 1413 (1956); 105, 904 (1957).

[2] D. Mauri, H.C. Siegmann, P.S. Bagus, E. Kay. J. Appl. Phys. 62, 3047 (1987).

[3] A.P. Malozemoff. Phys. Rev. B 35, 3679 (1987).

[4] A. Scholl, M. Liberati, E. Arenholz, H. Ohldag, J. Stöhr. Phys. Rev. Lett. 92, 247201 (2004).

[5] C.L. Chien, V.S. Gornakov, V.I. Nikitenko, A.J. Shapiro, R.D. Shull. Phys. Rev. B 68, 014418 (2003).

[6] J. Nogues, J. Sort, V. Langlais, V. Skumryev, S. Suriñach, J.S. Muñoz, M.D. Baró. Phys. Rep. 422, 65 (2005).

[7] F. Radu, H. Zabel. Tracts Mod. Phys. 227, 97 (2008).

[8] M.D. Stiles, R.D. McMichael. Phys. Rev. B 59, 3722 (1999).

[9] E. Fulcomer, S.H. Charap. J. Appl. Phys. 43, 4190 (1972).

[10] T.C. Schulthess, W.H. Butler. Phys. Rev. Lett. 81, 4516 (1998).

[11] M.D. Stiles, R.D. McMichael. Phys. Rev. B 63, 064405 (2001).

[12] V.I. Nikitenko, V.S. Gornakov, L.M. Dedukh, Yu.P. Kabanov, A.F. Khapikov, A.J. Shapiro, R.D. Shull, A. Chaiken, R.P. Michel. Phys. Rev. B 57, R8111 (1998).

[13] V.I. Nikitenko, V.S. Gornakov, A.J. Shapiro, R.D. Shull, K. Liu, S.M. Zhou, C.L. Chien. Phys. Rev. Lett. 84, 765 (2000).

[14] V.S. Gornakov, Yu.P. Kabanov, O.A. Tikhomirov, V.I. Nikitenko, S.V. Urazhdin, F.Y. Yang, C.L. Chien, A.J. Shapiro, R.D. Shull. Phys. Rev. B 73, 184428 (2006).

[15] A.P. Malozemoff, J.C. Slonczewski. Magnetic Domain Walls in Bubble Materials. Academic, N.Y. (1979). 382 c.

[16] A. Hubert, R. Shafer. Magnetic Domains. Springer, Berlin (1998). $686 \mathrm{c}$.

[17] R.D. Shull, A.J. Shapiro, V.S. Gornakov, V.I. Nikitenko, J.S. Jiang, H. Kaper, G. Leaf, S.D. Bader. IEEE Trans. Magn. 37, 2576 (2001).

[18] J.S. Jiang, S.D. Bader, H. Kaper, G.K. Leaf, R.D. Shull, A.J. Shapiro, V.S. Gornakov, V.I. Nikitenko, C.L. Platt, A.E. Berkowitz, S. David, E.E. Fullerton. J. Phys. D 35, 2339 (2002).

[19] V.S. Gornakov, Yu.P. Kabanov, V.I. Nikitenko, O.A. Tikhomirov, A.J. Shapiro, R.D. Shull. JETP 99, 602 (2004).

[20] S. Mangin, C. Bellouard, S. Andrieu, F. Montaigne, P. Ohresser, N.B. Brookes, B. Barbara. Phys. Rev. B 70, 014401 (2004).

[21] X. Portier, A.K. Petford-Long, A. de Morais, N.W. Owen, H. Laidler, K. O’Grady. J. Appl. Phys. 87, 6412 (2000).

[22] A.N. Dobrynin, F. Maccherozzi, S.S. Dhesi, R. Fan, P. Bencok, P. Steadman. Appl. Phys. Lett. 105, 032407 (2014).

[23] Z. Tian, C. Zhu, Y. Liu, J. Shi, Z. Ouyang, Z. Xia, G. Du, S. Yuan. J. Appl. Phys. 115, 083902 (2014).

[24] L.H. Bennett, R.D. McMichael, L.J. Swartzendruber, S. Hua, D.S. Lashmore, A.J. Shapiro, V.S. Gornakov, L.M. Dedukh, V.I. Nikitenko. Appl. Phys. Lett. 66, 888 (1995).
[25] M.A. Lebyodkin, N.P. Kobelev, Y. Bougherira, D. Entemeyer, C. Fressengeas, V.S. Gornakov, T.A. Lebedkina, I.V. Shashkov. Acta Mater. 60, 3729 (2012).

[26] I.V. Shashkov, M.A. Lebyodkin, T.A. Lebedkina. Acta Mater. 60, 6842 (2012).

[27] M.A. Lebyodkin, I.V. Shashkov, T.A. Lebedkina, V.S. Gornakov. Phys. Rev. E 95, 032910 (2017).

[28] M.A. Lebyodkin, T.A. Lebedkina, I.V. Shashkov, V.S. Gornakov. Appl. Phys. Lett. 111, 032407 (2017).

[29] N.N. Hsu, F.R. Breckenridge. Mater. Eval. 39, 60 (1981).

[30] H. Lamb. Proc. Roy. Soc. (London) A 93, 114 (1917).

[31] I.A. Viktorov. Rayleigh and Lamb waves: physical theory and applications. Plenum Press, N.Y. (1967). 169 c.

[32] S.V. Kuznetsov. Acoust. Phys. 60, 95 (2014).

[33] J. Slack. J. Appl. Phys. 31, 1571 (1960).

\section{Редактор Ю.Э. Китаев}

